\title{
Methodological Aspects of the Formation of the Innovative Development Model of Agriculture
}

\section{Andrey Poltarykhin', Tatyana Tarabukina², Angelina Blagodatskaya3, Andrey Yudin4, Alina Veshkurova5, Alexey Adelfinskiy ${ }^{6}$, Stanislava Tokareva $7^{*}$}

'Plekhanov Russian University of Economics, Stremyannyj lane, 36, Moscow, 115054, Russia

${ }^{2}$ Institute of Agro-Biotechnologies FRC Komi, Rucheynaya str., 27, Komi Republic, Syktyvkar, 167023, Russia

${ }^{3}$ Moscow State University of Civil Engineering, Yaroslavl highway, 26, Moscow, 129337, Russia

${ }^{4}$ Institute of Agro-Biotechnologies FRC Komi, Rucheynaya str., 27, Komi Republic, Syktyvkar, 167023, Russia

${ }^{5}$ Russian University of Transport, Obraztsova st., 9, bldg. 9, Moscow, 127994, Russia

${ }^{6}$ Moscow State Pedagogical University, 1/1 Malaya Pirogovskaya Str., Moscow, 119991, Russia

${ }^{7}$ Southwest State University, 5o Let Oktyabrya Street, 94, Kursk, 305040, Russia

Study Area: Moscow, Russia

Coordinates: $55^{\circ} 45^{\prime} 21^{\prime \prime} \mathrm{N} 37^{\circ} 37^{\prime} 2^{\prime \prime} \mathrm{E}$

Keywords: Functioning of agro-industrial formation, Agro-industrial formation.

\section{Introduction:}

Currently, many programs of modernization of enterprises are being phased out and cancelled. So, a group of large companies is forced to "freeze" the implementation of investment projects (Fomin et al., 2019; Magsumov, 2017; Goreliket al., 2021).

The problems in the agricultural sector are really quite deep, so there is an objective need to transform the Russian economy and transfer it to the innovative path of development. The basis is the need for scientific justification and practical application of new agroindustrial units that promote vertical integration, combining agricultural production with processing, marketing, supply, and agricultural service. The development of these areas is due to an objective economic process, associated, on the one hand, with the social division of labour and its specialization, scientific and technological progress, and natural and economic

\section{Abstract}

The global financial crisis has been reflected in Russia, and especially in the agricultural sector. As a result of a decrease in the purchasing power of the population for food, the purchase price of retail chains fell, and in the face of rising prices for products and services of natural monopolies, the cost of production increased, which, of course, affected they efficiency of agricultural enterprises. Thus, the chief objective of the present paper is to discuss the methodological aspects of the formation of the innovative development model of the agricultural sector. The global financial crisis can rightfully be considered the most profound and dramatic over the past few decades of the global economy. The main cause of the crisis lies in the particular cyclical development of the world economy. Most economically developed countries, primarily the United States and Western Europe, after the peak of technological and economic development at the end of the twentieth century. enter a new cycle - a cycle of lowering economic growth, and according to many experts, even in a recession. A significant decline is observed in the USA and Europe in terms of GDP growth rates, business activity indices, consumer confidence, etc. Therefore, the problem of cyclical development in the current crisis can be confidently described as a structural transformation of the global economy in anticipation of growth due to the new future in the near future way of life.

conditions. On the other hand, with a need for interaction between specialized sectors and types of agricultural and industrial production. Agrarian organizations enter into this unifying movement, seeking to reduce the risk associated with production and its dependence on climatic conditions, the spontaneity of the agricultural product market, the dictates of processing organizations, and the need to increase the competitiveness of production (Pleta et al., 2020; Karpenko et al., 2021; Barmuta et al., 2020).

Processing and serving organizations also strive to secure stable incomes due to the availability of a reliable raw material base, better use of raw materials, improving the quality of their products, reducing their cost and gaining sales markets. The choice of this or that form of integration depends on the industrial and economic situation in the region, the state of the food market, the forms of capital pooling and their participation in management, and the capabilities of the parent company. However, regardless of

*Corresponding Author: 
the form chosen for all agro-industrial formations, the main thing is that they combine the entire reproduction process, from the agricultural producer to the consumer of the finished product. The participants in the system ensure the promotion of the product as a property of the corporation along the whole chain: production - processing - implementation, which ultimately contributes to the achievement of the effect in the fight against the crisis (Nechaev, 2010; Mazur et al., 2016; Belousova et al., 2021; Yemelyanov et al., 2018; Lyubashits et al., 2020).

\section{An analysis:}

The presented technological chain will not have a positive effect without the economic influence of the state, science, education, developed infrastructure, etc. Therefore, we propose using a cluster approach as a tool to combat the global crisis, which is based on taking into account the positive synergetic effects of regional agglomeration, i.e. the proximity of the consumer and the manufacturer, network effects and the diffusion of knowledge and skills due to the migration of personnel and the separation of the business. There are no boundaries between sectors and activities and they are all considered in conjunction. For administrations: the number of taxpayers and the tax base are increasing (small and medium-sized business management centres are usually located in the same territory as the business itself, unlike vertical corporations), a convenient tool for interacting with the business appears, and dependence on individual business groups, there are reasons for diversifying the economic development of the territory.

For business: human resources infrastructure is improving, infrastructure for research and development is appearing, costs are being reduced, and opportunities are emerging for more successful entry into international markets. The region's agribusiness development strategy should be based on the study of the process of creating a "cluster value chain" of manufactured products, which will allow to identify the missing stages, eliminate duplicate subsystems, and optimize the cluster chain that contributes to the competitive advantages of agroindustrial production - in particular, subcomplexes in the region as a whole (Fig.-1).

Macro-characteristics make it possible to substantiate the specialization and concentration of crops and raw materials in the raw material zones of the processing industry and the economic growth rates of the considered raw material zones. Based on the economic and social potential, the availability of the raw material base of processing capacities and sales markets, strategic directions for the development of clusters are formed within the framework of food sub-complexes of the region. Microanalysis considers the "cluster value chain" of the region, where the initial information on the processes of expanded reproduction is collected, while the regional statistics serve as the basis for the analysis. Comparing the results of macro-and microanalysis, they form clusters within the framework of food sub-complexes of the region (Ivanova, 2020; Pogosyan, 2019; Polyakova et al., 2019; Pleta et al., 2020; Ivanova et al., 2019; Rahman \& D'K Novikova Freyre Shavier, 2018; Rahman \& Bobkova, 2017; Bespalova et al., 2021; Demichev et al., 2021).

With a carefully developed and streamlined economic mechanism of a vertically integrated structure, the cluster should provide:- equivalence of economic relations between the structural units of the formation, strengthening the self-supporting interest of units in improving the efficiency of agricultural production, the economic interest of participants in deepening integration processes, optimal combination and rational use of main production resources and funds (land, labour, material, financial), accelerating the development of expanded reproduction, be investment attractive for external and internal investors.

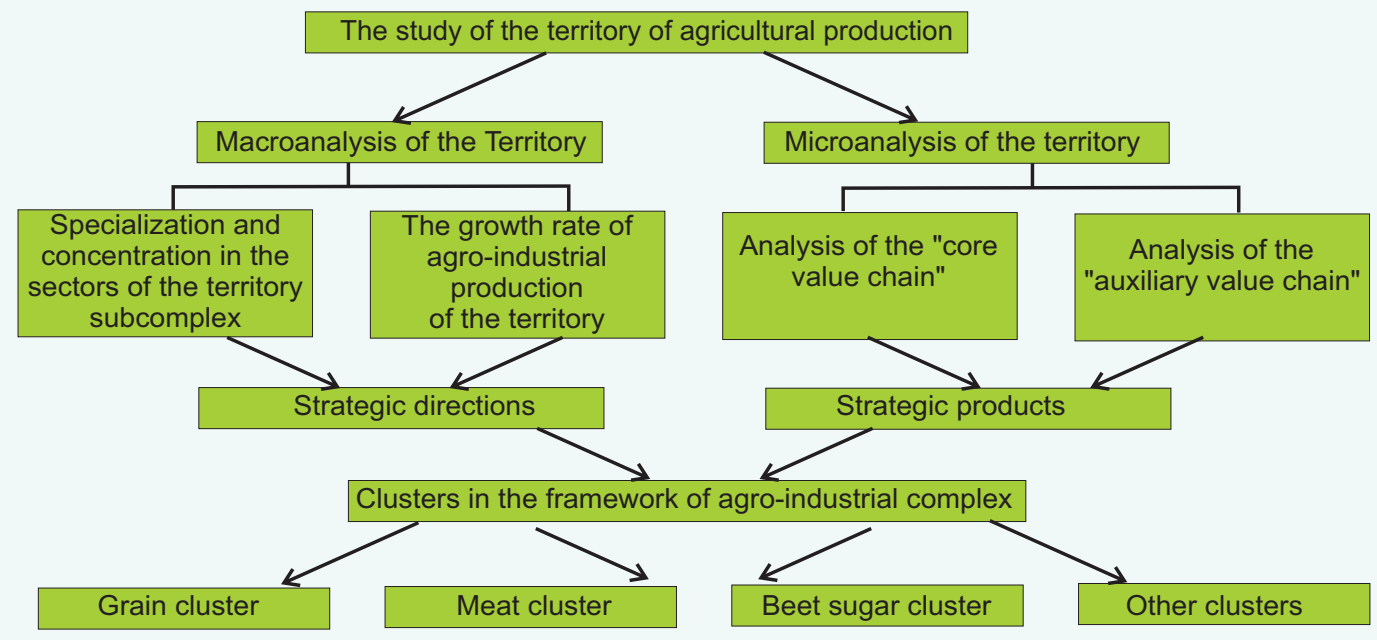

Figure-1: Formation of clusters in food subcomplexes of the agricultural sector of the region 
Table 1: Strategic positioning of the regional food cluster (on the example of a sugar beet cluster)

The basic provisions for the formation of clusters in the sugar

beet subcomplex of the region

- Work in certain segments of the regional market

- Development of regional sugar beet producers

- Assisting in the development of seed production to increase the competitive potential of the region

- Development of the potential of processing enterprises (sugar factories) through the introduction of new technologies and the use of new technology

- Increase in investment flows in agricultural sector of the region

- Creation of a stable information field with the provision of twoway communication between consumers and manufacturers of products of the sub-complex

- Interaction with public authorities to jointly determine measures of influence and a package of legislative acts to achieve these goals
Strategic opportunities

- Meeting the growing needs of clusters in R\&D, new technologies, high-quality material and technical resources

- Formation of sustainable contacts with financial and credit institutions based on the formed image of the cluster

- Development of sustainable trade relations with suppliers of material and technical resources

- Promoting the development of our own material and technical base of beet production and processing enterprises

\section{We found:}

As domestic and foreign practice shows, for the creation and effective functioning of an agro-industrial formation, the following basic principles must be observed: voluntary choice of a partner and economic feasibility, which allows optimizing the composition of integrated formations; integration from below, that is, association at the initiative of the economic entities themselves without pressure from management structures; the impact of the state on the integration process only by creating economic conditions that ensure its effectiveness, or on the basis of the participation of the state body as an equal partner of associations; organizational integrity of integrated structures with common strategies, tactics, goals and objectives of development; highlighting the leading link and priority areas for improving integrated formation; equal economic conditions for all participants in integrated formations, both during their creation and during their functioning; the combination of not only organizational and economic structures, but also under certain conditions of their capital; collective property management, which increases the interest and responsibility of each partner in joint activities, involves commercial capital in the process of agricultural integration, and ensures an influx of investment in the agricultural sector (Poltarykhin, 2020; Litvinenko et al., 2018; Dudukalov et al., 2016; Klochko \& Zelinskaya, 2019).

Currently, without additional resources and measures for innovative development, it is impossible to form a balanced system of material and technical support. For example, in beet-growing farms, there is a high physical and moral deterioration of existing equipment and a low rate of its renewal, a low level of scientific potential to create new equipment, and the absence of its own agricultural machinery based in the region (Plaskova et al., 2019; Glotko et al., 2020; Johnson, 2020). Practice indicates the imperfection of integration and cooperation for solving the problems of innovative development of the material and technical support system for the agro-industrial complex of the region as a whole, while the role of the state is reduced to stimulating individual organizations. There is no mechanism for systemic innovative development of the region. Therefore, a complex solution to the problem of innovative development of product subcomplexes is the formation of a cluster policy (Table-1).

As a result of the structural fragmentation of the sugar beet subcomplex enterprises in the region, the seasonal activity of beet farming, the low level of transport infrastructure, and, as a result, weak investment attractiveness, we identified factors that significantly affect the formation of the sugar beet cluster (Fig.-2).

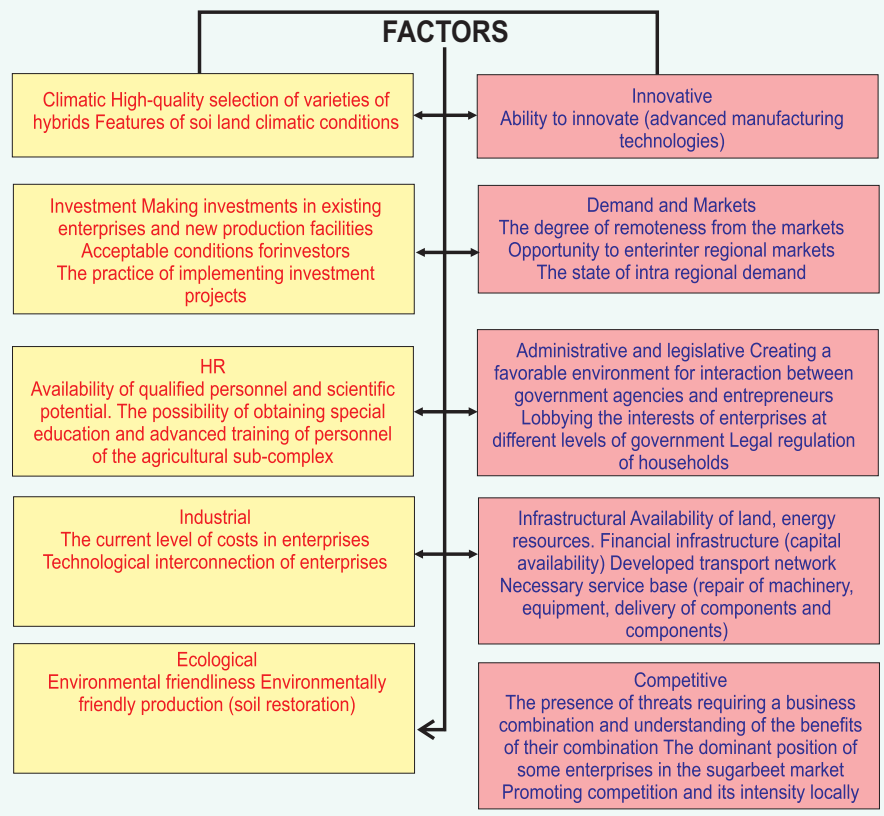

Figure-2: Factors of cluster formation and development

The following conditions are necessary for the formation and development of competitive product 
clusters in the regions:

1. Developed a competitive environment, contributing to the interest of enterprises in reducing production costs.

2. The presence of common economic interests of cluster members.

3. A common corporate culture that ensures the long-term interaction of cluster members.

4. Formation of cluster members, including enterprises for the production of products with high added value and maximum complexity of the processing of raw materials.

5. Legislative support of the interests of the state in the production of products with high market potential.

Taking into account the above conditions for the formation of a cluster, we recommend a scheme for the interaction of agricultural enterprises in a cluster structure. It should be noted the lack of an unambiguous variant of the cluster structure, its content depends on the location and formation of the product orientation of the cluster, transport infrastructure and other factors. In addition, the functioning of a competitive product cluster includes four successive stages.

The first is the analysis and diagnosis of the conditions for the formation of a cluster based on marketing research, motivation of potential participants, the state of their capital and resources, assessing the prospects for the further development of participating enterprises. It assesses the possibility of forming a cluster and the presence of interested participants.

Marketing research includes studying the market of goods and services, supply and demand factors, price dynamics of products, analysis of competitors and assessment of the competitive advantages of enterprises. When studying the market, the following sections can be distinguished (Dunets, 2019; Frolova et al., 2020; Prodanova et al., 2019).

1. Assessment of the uncontrolled aspects of the macroenvironment, which includes economic (orientation and structure of the national economy, inflation, tax policy, financial system and purchasing power of the population), natural (climate, availability of raw materials, ecology), political (socio-political structure, level, feature and degree of implementation of the legislation), technological (level of scientific and technical progress, new standards of production and consumption), international (world market, dynamics of world prices), socio-cultural and demographic (cultural values, traditions, educational level and degree of population migration) aspects.

2. Assessment of the competitive advantages of production in the Altai Territory in relation to other regions of the country and foreign countries. Competitive advantages are expressed in the cost and sales price of the product, more flexible production, which allows you to immediately respond to emerging market needs, as well as in the degree to which innovations are introduced into agricultural production.

3. Assessment of the competitiveness of clusters in the grocery subcomplex at the regional level. It reveals the degree of intra-industry competition by monitoring the actions of potential competitors and, on the basis of cooperation, involves the development of a joint cluster strategy for the regional food sub-complex.

4. The influence of the price factor, which is the most important in determining the competitive advantages of enterprises. The price level influences the attraction of new customers, the increase in purchases, the retention of buyers by stimulating repeat purchases.

5. Analysis of demand for products. You should evaluate how the offer meets customer needs.

The motivation of potential participants in the future cluster structure is due to their functioning and sustainable development, resource requirements, investment attractiveness, long-term cooperation on mutually beneficial conditions, etc. The interconnection of enterprises increases their competitiveness in the market and interdependence. The main aspect of enterprise development strategy with increasing market share and expanding production activity is the need for investment (Gorbunov, 2003; Zakharov et al., 2020).

An analysis of the state of capital and resources of cluster participants involves the determination of capital and its structure, the identification of hidden reserves, financing potential, the volume of working capital, its turnover, liquidity, investment intensity factor, etc. Personnel composition (quality, performance, degree of participation in work, enterprise climate and pay policy). The result of such an analysis is to ensure the optimal balance of updating, maintaining and developing the necessary qualitative and quantitative composition of the personnel of enterprises in accordance with the planned activities of the cluster organization, as well as determining the size, structure of fixed assets, the dynamics of their development, indicators of the cost of maintaining the equipment, its degree of deterioration the optimal location of production facilities, the level and quality of production technologies, mobility and flexibility of the production cycle, etc.

Assessment of the prospects for further development of the cluster includes a forecast of the negative consequences of the interaction of enterprises according to the criteria: differences in the pricing policy of individual enterprises, abuse of the position of leading enterprises, lack of level of corporate activity of participants in the clusterstructure.

The second stage - the development of a mechanism for the formation of a cluster structure, includes the following conditions:

1. Identification of participants in the integration processes that form the cluster structure and affect the value chain in the cluster (for example, seed and beet-growing farms, sugar factories, sugar trading companies) with the definition of their level of interdependence to create a cluster, advanced specialized educational and research organizations providing training for the necessary personnel, industrial infrastructure enterprises (energy supply, transport, 
communications, marketing and advertising companies, leasing organizations, banks and other financial institutions).

2. Definition of the principles of cluster functioning on the basis of legal independence, maintaining economic and legal independence, the common strategic goal of the participants, a joint system for coordinating the activities of enterprises, unified corporate culture of the cluster (a unified system of norms and values, evaluating results, cohesion of cluster members, coordination), integration relationship.

3. Development of regulations and rules for the functioning of the cluster based on the distribution and coordination of production and business functions, the possibility of transferring part of these production functions to other cluster members based on outsourcing: a contractual system of enterprise interaction, an agreement on the degree of joint activity.

4. Development of provisions on the interconnection and interdependence of participants, based on the non-property principle of interaction: on the basis of technological ties, using a single infrastructure base, logistical support of each other, and joint marketing activities. In this case, it is necessary to take into account the conditions for the enterprise to enter the cluster and exit from it with the consequence of further functioning, as well as the standards of cluster ethics.

5. Identification of the personnel potential of the participants includes the availability of qualified personnel of the cluster enterprises and its stability, calculation of the complexity of the main types of work, personnel requirements and the possibility of replenishment of personnel.

The third stage - the functioning of the cluster structure, involves:

1. Organization of the management structure in the form of a coordination council (representatives of structure-forming seed and beet-growing farms, sugar factories, universities, research institutes, infrastructure enterprises) for interaction, distribution of responsibility between participants. The Coordination Council oversees the longterm cluster development strategy, the direction of the cluster, distributes tasks between the Council and the cluster members (Table-2).

2. Organization of the economic structure - the distribution of production functions, the creation of missing production. The organization of new industries is possible on the basis of functioning cluster enterprises or by creating a new industry. The mechanism of joint activity of cluster members is determined.

3. Determining the extent of joint activities of the cluster enterprises (mutual supplies, product range, research work, etc.) based on minimizing costs.

4. Formation of norms and rules of interaction between cluster members (time, terms, quantity and volumes of supplies, the possibility of changing these parameters without coordination with each other). Provided: common technological standards; unified approach to the production structure; quality management system.

5. Analysis of the formation of personnel at the enterprises of the cluster. It includes the quality of staffing (the level of staff qualifications and their stability, staffing and the possibility of training employees of cluster enterprises, the complexity of the main types of work), the level of interaction between enterprises and educational institutions, the forecast of staffing requirements and ways to attract specialists.

The fourth step is the assessment of socio-economic efficiency and further strategic development of the cluster, determines the effective indicators of the economic activity of the cluster members, the share of the increase in the number of enterprises and organizations in the cluster, the increase in production in the cluster with high added value, the increase in the share of small and medium enterprises, staffing, the volume of attracted investments in the cluster, the volume of cluster production.

Consequently, the task of the agro-industrial cluster created within the framework of food subcomplexes is to give the production of agricultural products a complete form of organization and management with a rational solution of technical, technological, economic issues related to the receipt of raw materials, procurement, transportation, processing, storage and sale finished products (Poltarykhin, 2019).

The study of clustering experience in other sectors of the economy, international experience allowed us to develop a conceptual model for the formation of a strategy for a regional sugar beet cluster. This model is universal and can be used to build agro-industrial clusters of both intraregional and inter-regional orientation. The strategy of the agro-industrial cluster can be outlined and implemented only in the context of the coordinated interests of partners, government, and business and will increase the competitiveness of the agricultural sector of the region.

Studies of the theory of the cluster approach confirm the need for determining the nuclei of development of the created structure. Since it is necessary to identify the base enterprises (leading enterprises), identify key partners, identify regional opportunities (conditions of production factors, their quality and degree of specialization; conditions for competition and strategic development; conditions of demand; related or supporting industries), identify priority sales markets products. In this case, "points of growth" are sugar factories, which act as poles of concentration of factors of production of raw materials and capital, which ensure effective return on investment within the cluster as a whole and the raw material zone in particular. At the same time, the development of the economic core is impossible without the restoration of the sugar beet seed production system and the implementation of the intensive factors of sugar beet farming.

Within the framework of the beet-sugar cluster being created, it is necessary to deepen vertical integration, since the production of sugar beets and sugar does not constitute a completed technical and technological space. Moreover, the role of industries in the production of raw materials and final products in modern integration processes is fundamentally changing. If a few years ago, integration was 


\section{TECHNOSCIENCE ARTICLE}

an attempt to smooth out the imperfection of the market mechanism in the sugar beet subcomplex, then as part of the creation of the cluster, there was an urgent need to improve equipment and technologies in all sectors of the subcomplex of the region, as well as to increase the competitiveness of the domestic market for the needs of the agricultural sector.

As part of the cluster structure, we also propose the use of scientific and educational potential. Today, many research institutes, higher education institutions and their structural divisions to a greater extent have no practical connection with the real sector of the economy. Quite a few orders for scientific developments, new technologies, personnel, etc. The formation of a cluster with the participation of science and education (research institutes, universities, colleges, design institutes, etc.) gives advantages to both production structures and the scientific and educational institutions themselves. The enterprises of the technological chain realize a synergistic effect on the basis of technical and technological re-equipment, helping the university to solve various applied problems. In turn, universities are given the opportunity to more fully use the educational, scientific and technical potential in the field of basic research and the provision of educational services. There are opportunities for the practical application of the knowledge gained, the expansion of the scope of scientific activity, the receipt of funds for development through the implementation of consulting and other services, the employment of specialists who have graduated from this educational institution, at enterprises in their speciality (the latter also directly applies to secondary specialized educational institutions). In addition, an important aspect for the university is the presence of relations with enterprises in the real sector of the economy as one of the main accreditation indicators presented by the Higher Attestation Commission (Nechaev, 2010; 2003).

An equally important element of the cluster structure is a developed infrastructure, including financial and credit organizations (banks, insurance companies, investment funds), service and auxiliary organizations (marketing, consulting, legal, procurement, leasing companies, logistics infrastructure, engineering companies). The conducted studies allow us to conclude that its functioning occurs in the absence of full-fledged market infrastructure, an important component of which is a network of district and inter-district wholesale markets. That is why among the main areas of work of the beet sugar cluster, it is advisable to distinguish the following. Firstly, the development of the regional market infrastructure, which involves solving a set of organizational issues, including the organization in the region of a network of district and interdistrict wholesale markets and monitoring their work; implementation of a competitive sugar procurement system for federal and regional state needs; preparation of
Ambient Science, 2021: Vol. 08(2); 30-37 DOI:10.21276/ambi.2021.08.2.ta03

projects for the creation of market infrastructure institutions, as well as service and support purposes (marketing, consulting, law firms, etc.).

Secondly, information support, which includes the creation of a computer network with a data bank on the regional sugar market, the collection and processing of incoming information, the dissemination of information about sugar availability, current and forecast prices, the organization of training for sugar beet cluster participants in the basics of agribusiness, marketing, and stock trading.

Thirdly, the cluster's activity should be based on the results of comprehensive marketing research, involving the analysis of the effectiveness of sugar beet production as a source of trade resources for the regional market and determining the market capacity.

The key element of the regional agricultural cluster structure is government bodies and public organizations. State participation should represent a system of economic relations, including a set of forms and methods of multilevel budget funds formation and their use for financing targeted agricultural and food programs, R\&D, etc. The organizational and economic mechanism of state participation in a cluster structure should represent a threeunit system: organizational, managerial, economic and legal.

The organizational and managerial unit is represented by administrative and managerial structures coordinating the development of sugar beet production, price marketing services, a system of information and consulting centres, a system of wholesale and retail markets, special credit institutions, integrated groups, public structures, etc. The economic unit operates through price, credit -financial, tax and insurance leverage. Its sources are budget financing (investments), leasing transactions, state loans, etc. The legal block is represented by current legislative acts, decrees, decrees, orders and decrees regulating the development of the cluster system. Blocks are interconnected by elements and components, including scientific support, accounting, analysis and control over the use of borrowed and budgetary resources.

Conclusively, the development and regulation of the regional wholesale market should be seen in the context of the targeted impact of federal and regional authorities, management on the production, sale of raw materials and finished products. Regulation involves the interaction of a complex of administrative, organizational, legal and economic mechanisms. The effectiveness of this interaction is determined by the optimality of combining the interests of three groups of participants in the sugar beet cluster: consumers, producers of raw materials and finished products, the state. Priorities, of course, should be given to consumers of finished products of the sugar beet subcomplex.

Thus, the organization of cluster structures will, in our 
opinion, make it possible to stimulate innovation processes, improve the investment climate of the sugar beet subcomplex industries and, thereby, increase its competitiveness. In all subcomplexes of the region, there are prerequisites for the creation of a territorial-production structure, which is based on the interaction of the scientific and educational sphere, agricultural enterprises, trade, the service sector and the state. Such a symbiosis will become a growth point for the entireagro-industrial production.

Conclusively, the development and regulation of the regional wholesale market should be seen in the context of the targeted impact of federal and regional authorities, management on the production, sale of raw materials and finished products. Regulation involves the interaction of a complex of administrative, organizational, legal and economic mechanisms. The effectiveness of this interaction is determined by the optimality of combining the interests of three groups of participants in the sugar beet cluster: consumers, producers of raw materials and finished products, the state. Priorities, of course, should be given to consumers of finished products of the sugar beet subcomplex.

Thus, the organization of cluster structures will, in our opinion, make it possible to stimulate innovation processes, improve the investment climate of the sugar beet subcomplex industries and, thereby, increase its competitiveness. In all subcomplexes of the region, there are prerequisites for the creation of a territorial-production structure, which is based on the interaction of the scientific and educational sphere, agricultural enterprises, trade, the service sector and the state. Such a symbiosis will become a growth point for the entire agro-industrial production.

\section{References:}

Belousova, M., Aleshko, R., Zakieva, R., Karabasheva, M., Gorovoy, S. \& Kozhemov, S. (2021): Development of equipment management system with monitoring of working characteristics of technological processes. I. App. Engineer. Sci., 19(1):186-192.

Bespalova, N.A., Sibirtsev, A.V. \& Yakovleva, T.S. (2021): Social system management in the context of interaction between society and the educational process in a technical university. Sovremennye issledovania Socialnyh Problem, 13(1):14-30.

Barmuta, K.A., Akhmetshin, E.M., Andryushchenko, I.Y., Tagibova, A.A., Meshkova, G.V., \& Zekiy, A.O. (2020): Problems of business processes transformation in the context of building digital economy. Entrepren. Sustain. Issue., 8(1):945-959.

Demichev, I.V. (2021): Virtuality and networking: about the sociocultural communities of the information age (Answer to M.G. Bresler's Monograph 'The Ontology of Network Existence'). Sovremennye Issledovania Socialnyh Problem,13(2):14-37.

Dudukalov, E.V., Rodionova, N.D., Sivakova, Y.E., Vyugova, E., Cheryomushkina, I.V. \& Popkova, E.G. (2016): Global innovational networks: Sense and role in development of global economy. Contemp. Eco., 10(4):299-310.

Dunets, A.N., Ivanova, V.N. \& Poltarykhin, A.L. (2019): Cross- border tourism cooperation as a basis for sustainable development: a case study. Entrepren. Sustain., 6(4):22072215.

Fomin, A.A., Shapovalov, D.A. \& Lepekhin, P.P. (2019): Digital agriculture as a driver of innovative development of AIC. Int. Agricul.J., 62(2):5.

Frolova, I.I., Nosov, V.V., Zavyalova, N.B., Dorofeev, A.E., Vorozheykina, T.M. \& Petrova, L.I. (2020): Labor opportunism as a blocking factor for the innovative development of industrial enterprises. Entrepren. Sustain. Issue., 7(3):2228-2242.

Glotko, A.V., Okagbue, H.I., Utyuzh, A.S., Shichiyakh, R.A., Ponomarev, E.E., \& Kuznetsova, E.V. (2020): Structural changes in the agricultural microbusiness sector. Entrepren. Sustain. Issue., 8(1):398-412.

Gorbunov, N.M. (2003): Interregional economic integration [Electronic resource]: Trends, factors and the mechanism of state regulation:Dis. Doc. Econ. Sci., 08.00.05. M .: RSL.

Gorelik, O.V., Brjanzev, A.Y., Safronov, S.L., Gritsenko, S.A. \& Bobkova, E. (2021): Influence of the age of cows on the dynamics of dairy efficiency depending on a breeding line. IOP Conference Series. Earth Environ. Sci., 677(4):042015.

Ivanova, V., Poltarykhin, A. \& Szromnik, A. (2020): State regulation of tariffs in the gas sector. J. Sec. Sustain. Issue., 9(3):c.909-917.

Ivanova, V., Poltarykhin, A., Szromnik, A. \& Anichkina, O. (2019): Economic policy for country's digitalization: A case study. Entrepren. Sustain. Issue., 7(1):649-661.

Johnson, M. (2020): Serious with the Wordplay: Battle Rap as a Critical Literacy Site and Model.J. Cul. Val. Edu., 3(2):24-41.

Karpenko, O., Stavytska, S., Artemenko, I., Sidanich, I. \& Prozhoha, I. (2021). Improvement of Mechanisms for State Management of Continuous Improvement of Quality of Provision of Medical Services in Ukraine. Siberian J. Life Sci. Agricul., 13(2):64-76.

Klochko, E.N. \& Zelinskaya, M.V. (2019): Ethno-economy in terms of digitalization of Russia. Aebmr-Adv. Econ. Busi. Manag. Res., 81:210-213.

Litvinenko, I.L., Klochko, E.N., Zelinskaya, M.V., Polyanskaya, O.A. \& Martynenko, N.K. (2018): Features of managing innovative clusters of modern Russia. Espacios, 39(31):1-23.

Lyubashits, V.Y.A., Razuvaev, N.V., Abramova, I.E., Fedorova, N.V. \& Benedyk, Y.S. (2020): Political institute of the State in the context of the historical and typological analysis. Revista Genero Direito, 9(3):726-741.

Magsumov, T.A. (2017): Family and school in Russia at the beginning of the 2oth century: Attempts to bridge the gap. Eu . L. Contemp. Edu., 6(4):837-846.

Mazur, V.V., Barmuta, K.A., Demin, S.S., Tikhomirov, E.A., \& Bykovskiy, M.A. (2016): Innovation clusters: Advantages and disadvantages. Int.J. Econ. Fin. Issue., 6(1S):270-274.

Nechaev, V.I. (2010): Economics of Industrial Poultry Farming. Pub. by: S.D. Fetisov, Krasnodar.

Nechaev, V.I. \& Khatuov, D.Kh. (2010): Improving the System of State Regulation of the Regional Economy. Pub. by: Krasnodar.

Nechaev, V.I. \& Trubilin, A.I. (2003): Organization of Agricultural Production with the Basics of Entrepreneurial Activity. Pub. by: Krasnodar.

Plaskova, N.S., Prodanova, N.A., Akhmetshin, E.M., HAYA, V.T., 


\section{TECHNOSCIENCE ARTICLE}

Pozdeeva, S.N. \& Dimitrov, I.L. (2019): Assessment of the investment attractiveness of innovative companies using the scenario method. Proc. 33rd Int. Busi. Info. Manag. Asso. Conf., IBIMA 2019 - Education Excellence and Innovation Management through Vision 2020, 7766-7773.

Pleta, T., Tvaronaviciene, M., Della Casa, S. \& Agafonov, K. (2020): Cyber-attacks to critical energy infrastructure and management issues: overview of selected cases. Insight. Reg. Develop., 2(3):703-715.

Pogosyan, V. (2019): Change and variability of phenomena in complex social systems. Wisdom, 13(2):95-103.

Poltarykhin, A., Ivanova, V. \& Ivanov, S. (2020): World experience in the formation and development of the "digital economy". Talent Develop. Excell., 12:c.372-384.

Poltarykhin, A., Nosov, V., Poletaeva, L., Avdotin, V., Grishin, V. \& Babakisiyev, M. (2019): Problems of the ecological system in Russia and directions for their solution based on economic and social development programs. J. Environ. Manag. Tour., 10(3):508-514.

Polyakova, A., Kolmakov, V. \& Yamova, O. (2019): Regional competitiveness response to innovation changes: Issues of evaluation. J. Urban Reg. Analy., 11(2):159-172.
Ambient Science, 2021: Vol. 08(2); 30-37 DOI:10.21276/ambi.2021.08.2.ta03

Prodanova, N., Savina N., Kevorkova Z., Korshunova L. \& Bochkareva N. (2019): Organizational and methodological support of corporate self-assessment procedure as a basis for sustainable business development. Entrepren. Sustain Issue, 7(2):1136-1148.

Rahman, P.A., \& D'K Novikova Freyre Shavier, G. (2018): Reliability model of disk arrays RAID- 5 with data striping. IOP Conference Series: Materials Science and Engineering, $327(2)$.

Rahman, P.A., \& Bobkova, E.Y. (2017): The reliability model of the fault-tolerant border routing with two Internet services providers in the enterprise computer network. J. Phy., Conf. Series, 803(1).

Yemelyanov, V., Yemelyanova, N. \& Nedelkin, A. (2018): Neural network for decision support to determine the operating mode of lined equipment. Matec Web of Conferences. 2018.

Zakharov, K.V., Terehova, A.A., Kozlov, V.N., Bobkova, E.Y., \& Grigoryants, I.A. (Problems of nature protection in Moscow. IOP Conference Series (2020): Earth Environmental Science, 548(5): 052031. 